\title{
Prediction of Localized Corrosion Damage of Some Machine Components by Means of Extreme Value Statistical Analysis*
}

\author{
By Yuichi ISHIKAWA, ** Toshinori OZAKI,** Nobuyoshi HOSAKA** \\ and Osamu NISHIDA**
}

\begin{abstract}
Synopsis
As a series of study to develop a procedure to make a quantitative evaluation of corrosion data, it is demonstrated that the extreme value statistical analysis can be successfully applied to various localized corrosion data acquired from machine components presently in service, and that corrosion life prediction can be done by examining the time dependence of predicted maximum depth of penetration.

The following localized corrosion data are obtained from the machine components in service: tuberculation of carbon steel feed water pipes for hydroelectric power stations, pitting and crevice corrosion of cupro-nickel heat exchanger tubes employed for a chilling machine using a reclaimed water as a coolant, and crevice corrosion of type 316 stainless steel swathed joints used for high speed liquid chromatography are analyzed thoroughly.
\end{abstract}

\section{Introduction}

In order to prevent corrosion failures of machines and structures, it should be known in advance when corrosion damages take place, and appropriate measures should be taken to mitigate the damages. The corrosion prediction is required to be made at both developmental and operational stages of machines. In newly designed machines, corrosion protection measures should be taken into account during their life span from development till operation. Also for machines already in service, measurements should be made on their present status. Based on the evaluation of these results, further corrosion prediction can be made as well as measures to prolong their service life.

The corrosion prediction during development of machines and their total service life prediction are usually made on the basis of experimental results obtained from test coupons and/or field experiences of similar machines. These processes give some ambiguity and risks to the prediction. The corrosion prediction after certain period of operation, i.e., remaining service life prediction, is made on the basis of inspection results while machines are either in or out of service. In this case it is hardly viable to examine the machines thoroughly because it requires a large amount of work to be done in determining the maximum depth of corrosion penetration. Therefore it is desirable to develop statistical means by which the whole scope can be reflected by the data obtained on small sampling.

So far extensive efforts have been made to develop measures to predict the corrosion behavior of machines and structures based on the results of measurement for a part of machines or test coupons. In the present paper, corrosion data obtained from a part of machine components are analyzed by means of extreme value statistics and the prediction of the maximum depth of corrosion penetration is illustrated for some cases of localized corrosion occurred in machine components while they have been in service.

\section{Extreme Value Statistical Analysis}

As an example, suppose that a large number of penetrations of corrosion pits have been measured on $1 \mathrm{~cm}^{2}$ area test coupons. To predict how long a pipe of similar material is likely to last is the problem of interest. Time for failure of the coupon is taken as the time for penetration of the first corrosion pit. Assume that the penetration times of the test coupons are distributed with some probability density function $f(t)$ and cumulative distribution function $F(t)$. If the pipe consists of $n$ pieces of test coupons, the time during which the pipe will operate without failure would be the time until the instant at which one of the pieces brings about a failure. Therefore the life span of the pipe $(t)$ is determined by the smallest value of the life span of the test coupons $\left(t_{i}\right)$,

$$
t=\min \left(t_{i}\right), \quad i=1,2, \ldots n .
$$

Then the distribution function of the life span of the pipe would be distributed according to the smallest order statistics; thus

$$
P(t)=1-(1-F(t))^{n}
$$

This means that high probabilities of pipe failures correspond to very small probabilities of coupon failures. Suppose the total area of the pipe is $100 \mathrm{~m}^{2}$. So that the ratio of its area to the $1 \mathrm{~cm}^{2}$ test coupons is $10^{6}$, then from Eq. (2), the median (50\%) probability for failure of the pipe is equivalent to a $7 \times$ $10^{-5} \%$ probability of coupon failure. Consequently either a very large number of coupons or coupons with a large area is necessary to provide a sufficiently accurate estimate of the tail of the coupon failure probability curve. However when the area of the machine is very large, corresponding test often would become impractical and in addition to that measurement of the depth of pits would bring another tedious task. Alternatively the observed failure probability curve obtained at higher failure probabilities must be fitted with sufficient confidence to some analytical expression to allow extrapolation down to the required low probabilities, as illustrated in Fig. 1.

* Originally published in Corrosion Engineering (Boshoku Gijutsu), 29 (1981), 502, in Japanese. English version received January 14, 1982. (C) 1982 ISIJ

** Mechanical Engineering Research Laboratory, Hitachi Ltd., Kandatsumachi, Tsuchiura 300. 


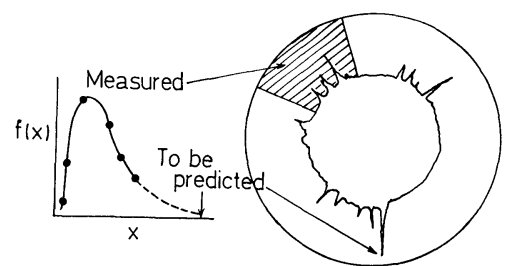

Fig. 1. Prediction of the maximum penetration depth at low probabilities.

If the tests on coupons are of insufficient duration for penetration to occur, then to establish the low probability tail of the failure probability curve the maximum pit depth as a function of time must be studied and extrapolated to the depth at which penetration occurs in the specimen or to a critical depth at which mechanical failure occurs when the component is stressed. In this case, determining the maximum pit depth in the specimen becomes the problem of interest.

It has been known that the area of the specimen strongly affects the maximum pit depth measured in the specimen. Considering a specimen that has many pits of varying depths and assuming that the initial pit depths have an exponential type distribution as demonstrated in Fig. 2 for a type 403 stainless steel component used for underground water for 5 years, then the problem of interest will be how the maximum pit depth, observed in the specimen, increases with increasing specimen size. According to Eldredge $^{1)}$ and Aziz, ${ }^{3)}$ the maximum pit depth is linear in the logarithm of the exposed area and extreme value statistics may be a means to solve the problem. The extrapolation of pittting data obtained from the laboratory or small portion of the structure to large scale field installations has been successfully carried out with the aid of extreme value statistics by Eldredge, ${ }^{1)}$ Hawn, ${ }^{2)} \mathrm{Aziz}^{3)}$ and Ishikawa. ${ }^{7)}$ Furthermore we have shown ${ }^{6}$ ) that the pitting corrosion life may be predicted by examining the time dependence of the maximum pit depth estimated by the extreme value statistical analysis of the pits observed in test coupons and component models.

According to Gumbel, ${ }^{8)}$ the asymptoic distribution $F(x)$ of the largest value for the exponential type is given by Eqs. (3) and (4).

$$
\begin{aligned}
F(x) & =\exp \left[-\mathrm{e}^{-y}\right], \quad-\infty<y<\infty \ldots \ldots \ldots \ldots \\
y & =\alpha(x-u) \ldots \ldots \ldots \ldots \ldots \ldots \ldots \ldots \ldots \ldots \ldots \ldots \ldots \ldots \ldots \ldots \ldots \ldots \ldots \ldots
\end{aligned}
$$

where, $y:$ the reduced variate

$u$ : the most probable value of the distribution

$1 / \alpha$ : a measure of variance given as $\sqrt{6} / \pi$ of the standard deviation of the distribution. The return period $T(x)$ is given by Eq. (5)

$$
T(x)=1 / 1-F(x)
$$

$T(x)$ is the number of observations required, such that on the average there is one observation equaling or exceeding $x$. For the exponential type of initial distribution, the return period $T(x)$ will converge for

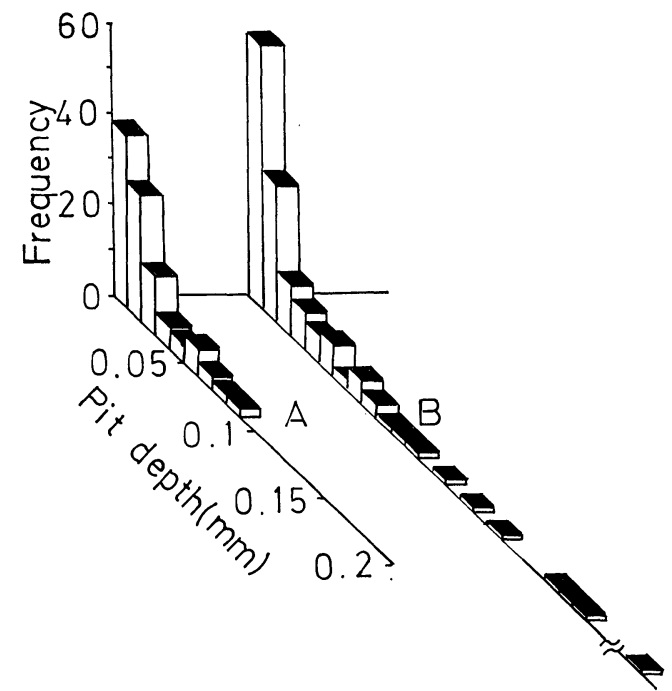

Fig. 2. An example of pit depth distribution (log normal distribution for a type 403 stainless steel component).

large values of $x$ toward:

$$
T(x)=\mathrm{e}^{y}
$$

so that

$$
y=\ln T(x)
$$

Consequently the largest values are given by Eq. (8) as a function of the return period.

$$
X \max =u+\ln T / \alpha
$$

Here the maximum pit depth observed on a specimen with fixed surface area is discussed so that the return period is the number of such specimens that must on the average be exposed in order to obtain a pit depth greater than the observed pit depth. Since the total surface area is proportional to the number of specimens, Eq. (8) predicts a logarithmic dependence of the maximum pit depth on the surface area. Prediction of corrosion behavior of the machine component may be made using the data observed for specimens and the return period given as the ratio of the exposed surface area of the component to the area of a specimen examined. Therefore extreme value probability plots are performed using the maximum pit depth values for each specimen and extrapolation of the resulted best fit line to $T$ yields the maximum pit depth expected in the component.

\section{Quantitative Evaluatian of Localized Cor- rosion Data Found in Some Machine Com- ponents in Service}

\section{Tuberculation of Feed Water Pipes for Hydroelectric Power Station}

Various feed water pipes (carbon steel) supplying cooling water to water turbines in hydroelectric power stations showed severe plugging problems because of tuberculation. Beneath tubercles large pits like localized corrosion was observed. Consequently prediction is required, for the service life of the pipes due 
to plugging or corrosion penetration, and extreme value statistical analysis is applied to the problem of corrosion penetration. Feed water pipes of 3 to 20 years in service were sampled from three power stations. The maximum penetration depth under tubercles was measured for each $1 \mathrm{~cm}^{2}$ unit of randomly sampled $10 \mathrm{~cm}$ long pipes. An example of tuberculation and penetration is shown in Photo. 1. The outermost layer of tubercles is covered with black and hard $\mathrm{Fe}_{3} \mathrm{O}_{4}$ layer and its inside is filled with black paste of $\mathrm{FeOOH}$ and golden colored soft amorphous layers. A ratio of the maximum height of tubercles to the maximum depth of penetration of metals was about 5 to 7 . The design velocity of water was set as 2.7 to $4.8 \mathrm{~m} / \mathrm{s}$ for these pipes and as seen from the nominal compositions of water in Table 1, the quality of feed water is very good, and considered to be not aggressive. However it should be noted that concentrations of $\mathrm{NO}_{3}^{-}$, total $\mathrm{Fe}$ and total carbonate are relatively high, and that the tubercles contain a large amount of $\mathrm{Mn}$ and $\mathrm{S}$ (sulfide). This leads to suggest that bacteria might be associated with this unique morphology of corrosion. The details will be discussed elsewhere. ${ }^{9)}$

Figure 3 shows extreme value probability plots of the maximum penetration depth. The plot shows a tailing in small values of the maximum penetration depth even though it fits the extreme value probability distribution. The unit area in which the maximum penetration depth is measured, is changed from 1 to 4,5 and $10 \mathrm{~cm}^{2}$. Then the distribution of the maximum penetration depth is measured and plotted in Fig. 4. When the unit area of the measurement increases to $5 \mathrm{~cm}^{2}$, a good linear fit is shown. This might be associated with the morphological charac- teristics of tuberculation. Consequently the extreme value statistical analysis is performed for the data determined in the unit area of $5 \mathrm{~cm}^{2}$. The results are shown in Fig. 4. From these plots, the maximum penetration depth is read for a $10 \mathrm{~m}$ long feed water pipe and plotted as a function of service period as shown in Fig. 5. Though the data is obtained from three different power stations using two different water systems, the results are well described by a

Table 1. Nominal compositions of the feed water.

\begin{tabular}{|c|c|c|c|}
\hline Power Station & B & G & $\mathrm{D}$ \\
\hline River & $\mathrm{E}$ & $\mathrm{F}$ & $\mathrm{F}$ \\
\hline $\mathrm{pH}$ & $6.9 \sim 7.0$ & $6.7 \sim 7.5$ & $6.8 \sim 7.2$ \\
\hline $\begin{array}{l}\text { Electrical } \\
\text { conductivity } \quad(\mu \mathrm{S} / \mathrm{cm})\end{array}$ & $50 \sim 55$ & $75 \sim 80$ & $55 \sim 70$ \\
\hline Total hardness (ppm) & $32 \sim 33$ & $32 \sim 40$ & $32 \sim 45$ \\
\hline Ca hardness (ppm) & $9 \sim 10$ & $14 \sim 17$ & $11 \sim 15$ \\
\hline $\mathbf{M}$ alkalinity $\quad(\mathrm{ppm})$ & $15 \sim 19$ & $13 \sim 19$ & $16 \sim 17$ \\
\hline $\begin{array}{l}\text { Dissolved oxygen } \\
\qquad(\mathrm{ppm})\end{array}$ & 4.8 & 4.5 & 4.7 \\
\hline (ppm) & 7 & $10 \sim 11$ & $8 \sim 10$ \\
\hline (ppm) & $\operatorname{Tr}$ & $0 \sim 0.4$ & $\mathrm{Tr}$ \\
\hline$(\mathrm{ppm})$ & $3.2 \sim 4.1$ & $5.2 \sim 6.4$ & $5.6 \sim 7.0$ \\
\hline (ppm) & nil & nil & nil \\
\hline$(\mathrm{ppm})$ & $7 \sim 13$ & $15 \sim 16$ & $9 \sim 10$ \\
\hline (ppm) & $0.6 \sim 0.8$ & $1.6 \sim 2.1$ & $1.7 \sim 1.9$ \\
\hline (ppm) & $0.2 \sim 0.6$ & $0.5 \sim 0.6$ & $0.4 \sim 0.6$ \\
\hline (ppm) & $12 \sim 14$ & $8 \sim 10$ & $8 \sim 9$ \\
\hline (ppm) & $48 \sim 57$ & $69 \sim 82$ & $64 \sim 69$ \\
\hline $\begin{array}{l}\text { Total carbonates } \\
\qquad(\mathrm{ppm})\end{array}$ & $1.79 \sim 18.4$ & $12.0 \sim 14.0$ & $9.7 \sim 11.1$ \\
\hline $\mathrm{HCO}_{3}^{-}$ & $1.43 \sim 14.5$ & $9.3 \sim 11.2$ & $8.0 \sim 8.4$ \\
\hline
\end{tabular}

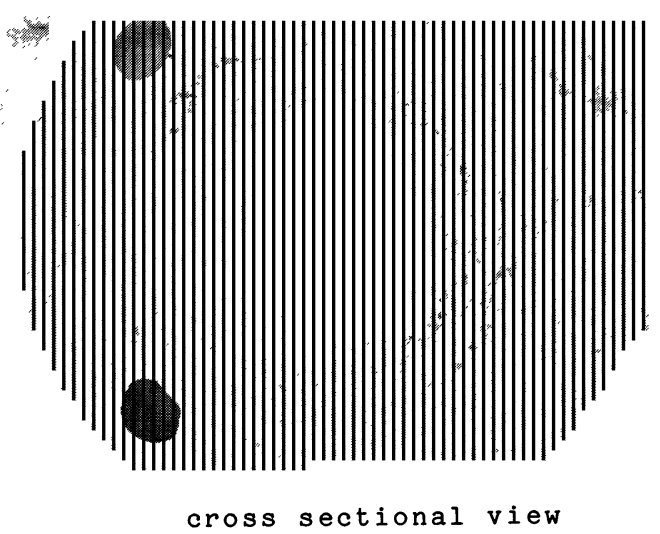

cross sectional view

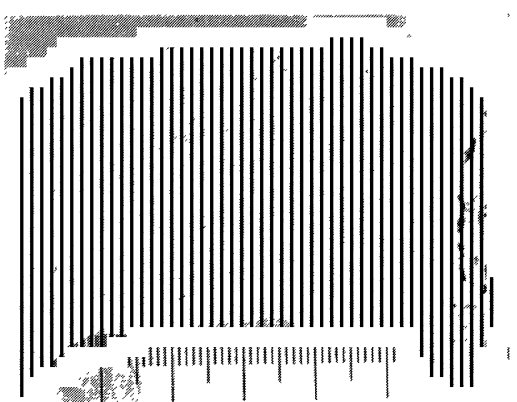

internal appearance
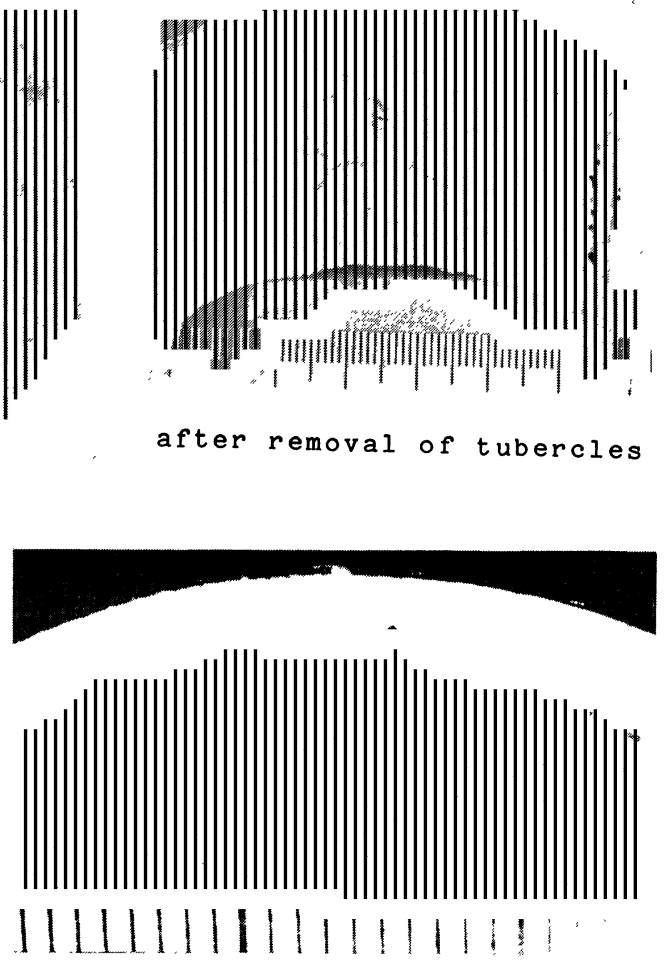

penetration under tubercles

feed water pipe (10 years in service). 

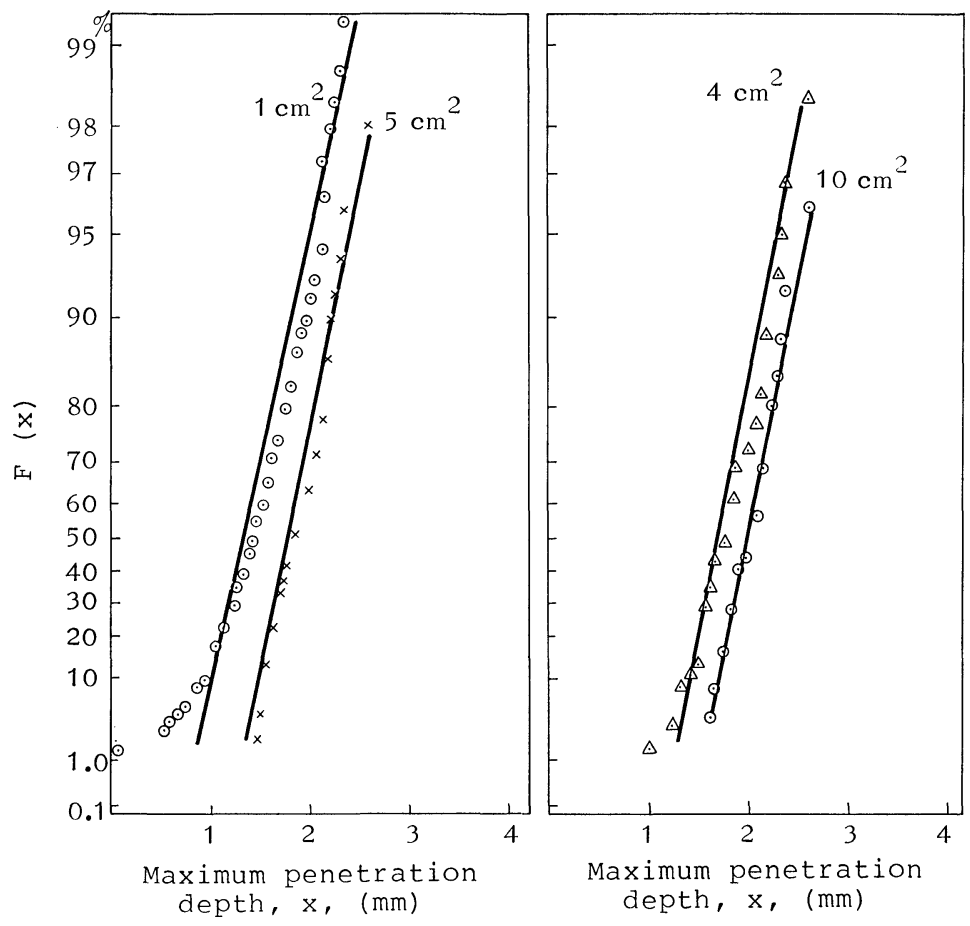

Fig. 3. Effect of specimen area on extreme value probability plots. (No. 1 pipe: 10 years in service at $B$ power station).
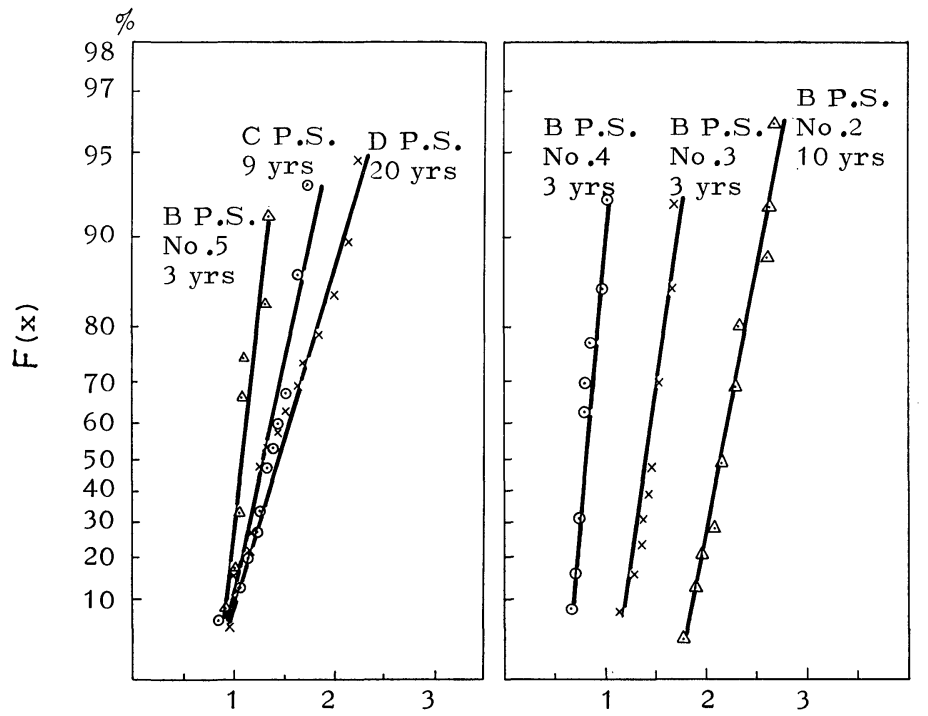

Maximum penetration depth $\mathrm{x}$ (mm)

Maximum penetration depth $x(\mathrm{~mm})$

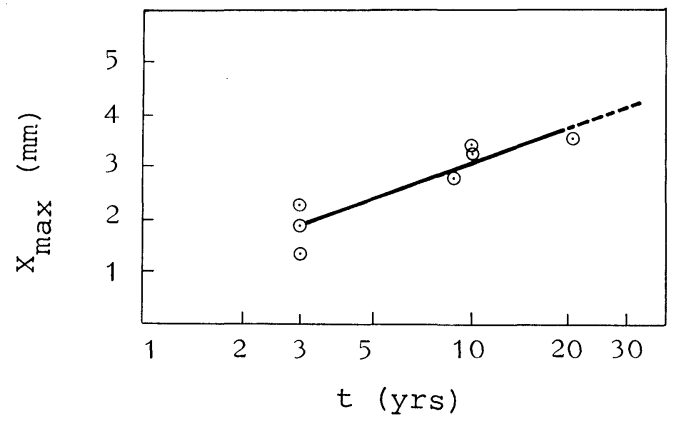

Fig. 5.

Time dependence of the predicted maximum penetration depth in the tuberculated feed water pipes.

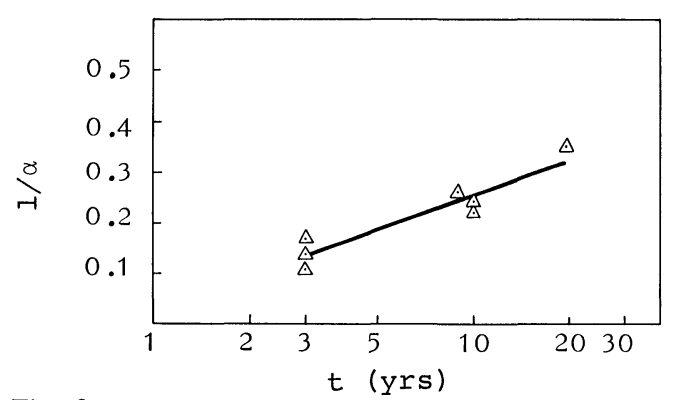

Fig. 6.

Time dependence of reciprocal of the scale parameter.

Fig. 4. Extreme value probability plots of the maximum penetration depth observed in the tuberculated feed water pipes.

logarithmic growth law in which $X_{\max }$ is proportional to the logarithm of service time.

$$
X_{\max }=2.29 \log t+0.79
$$

Differential form of Eq. (9) suggests that the rate of corrosion progress decreases with time. Moreover a scale parameter $\alpha$ in the extreme value probability plot decreases with service time and the slope of the least square fitted line becomes milder, suggesting a wider distribution of pit depth. Figure 6 shows a plot of $1 / \alpha$ vs. $\log t$. It is evident that change of $1 / \alpha$ with time is also described by a logarithmic rate law.
Based on the foregoing results, the leakage of the feed water pipe by corrosion is predicted to result in 5 years in service for a pipe of $2.5 \mathrm{~mm}$ thickness and in 25 years for $4.0 \mathrm{~mm}$ thickness.

\section{Pitting and Crevice Corrosion of Heat Exchanger Tubes for a Chilling Machine Using Reclaimed Water}

Since reclaimed water usually contains more organic and inorganic substances than the conventionally used cooling water does, penetration by pitting and crevice corrosion of heat exchanger tubes should be examined in addition to the problem of lowered ef- 
ficiency caused by deposition of silica scaling and microbiological slimes on heat transfer surfaces. One to three heat exchanger tubes (7/3 Cupro nickel, CNTF 3) were sampled and examined from the high temperature portion of a turbo chilling machine installed in a large supermarket. The machine was in service for $700 \mathrm{hr}$ a year and the water remained in the tubes for $6200 \mathrm{hr}$ a year. The reclaimed water is used as a coolant as well as supply for loss and for dilution of concentrated coolant by cyclic use. Table 2 shows variation of nominal compositions of the coolant. Concentration of impurities in the coolant goes up to 4 to 8 times and $\mathrm{pH}$ increases sharply during the off period and formation of $\mathrm{NH}_{4}^{+}$is observed. Increase of BOD indicates an increase in microorganics causing deposition of microbiological slimes. The system uses open air cooling tower and water velocity is designed to be lower than $3 \mathrm{~m} / \mathrm{s}$. A magnesium sacrificial anode is attached to the case of water chamber of the machine.

Specimens, $5 \mathrm{~cm}$ long, were sampled at both ends of the tube excluding initial $5 \mathrm{~cm}$ length of pipe at each end. Total length of the pipe being $4 \mathrm{~m}$, specimens were also sampled at either each $50 \mathrm{~cm}$ or $1 \mathrm{~m}$ interval. These specimens were divided into 4 portions resulting in a unit area of $5.5 \mathrm{~cm}^{2}$ for measurement. Deposits were removed by brushing with a nylon tooth brush and by immersing in a diluted sulfuric acid containing an inhibitor. Corrosion penetration depth was determined by a microscope with a dial gage. The deposit showed a thickness of $40 \mu \mathrm{m}$ after drying and consisted of silica, magnesia and slimes. Beneath the deposit many crevice corrosions took place, which consisted of a cluster of small pits

Table 2. Variation of nominal compositions of the reclaimed cooling water.

\begin{tabular}{lc|c}
$\mathrm{pH}$ & & $7.0 \sim 10.1$ \\
Electrical conductivity & $(\mu \mathrm{S} / \mathrm{cm})$ & $512 \sim 5000$ \\
$\mathrm{Ca}$ hardness & $(\mathrm{ppm})$ & $102 \sim 310$ \\
$\mathrm{M}$ alkalinity & $(\mathrm{ppm})$ & $40 \sim 210$ \\
$\mathrm{Cl}^{-}$ & $(\mathrm{ppm})$ & $86 \sim 756$ \\
$\mathrm{PO}_{4}^{3-}$ & $(\mathrm{ppm})$ & $\mathrm{Tr} \sim 12.2$ \\
$\mathrm{NH}_{4}^{+}$ & $(\mathrm{ppm})$ & $0.7 \sim 7.9$ \\
$\mathrm{SiO}_{2}$ & $(\mathrm{ppm})$ & $18 \sim 65$ \\
$\mathrm{TDS}$ & $(\mathrm{ppm})$ & $355 \sim 2450$ \\
$\mathrm{BOD}$ & $(\mathrm{ppm})$ & $68.7 \sim 74.5$ \\
$\mathrm{COD}$ & $(\mathrm{ppm})$ & $51 \sim 114$ \\
$\mathrm{~S} . \mathrm{S}$. & $(\mathrm{ppm})$ & $7.2 \sim 105$ \\
& &
\end{tabular}

as shown in Photo. 2. Pits were also observed in a gap between successive deposits. These were circular as shown in Photo. 2 and the number of pits was very small and relatively deep. These corrosions were not observed for the specimens sampled after 1 year in service, but were observed for those sampled after 2 years in service. The maximum penetration depth for pitting and crevice corrosion are plotted in an extreme value probability paper as shown in Figs. 7 and 8 , respectively. The maximum penetration depths

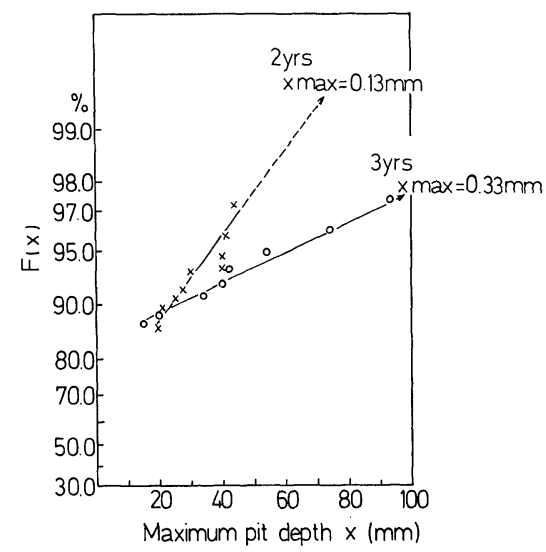

Fig. 7. Extreme value probability plots of the maximum pit depth observed for the heat exchanger tubes ( $X_{\max }$ was predicted at $T=4800$ ).

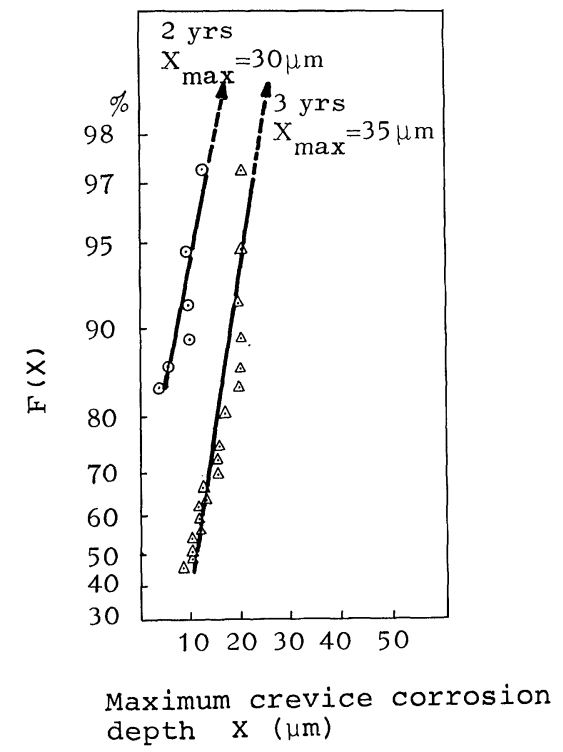

Fig. 8. Extreme value probability plots of the maximum crevice corrosion depth observed for the heat exchanger tubes $\left(X_{\max }\right.$ was predicted at $T=4800$ ).

Photo. 2. Localized corrosion observed for the heat exchanger tubes.

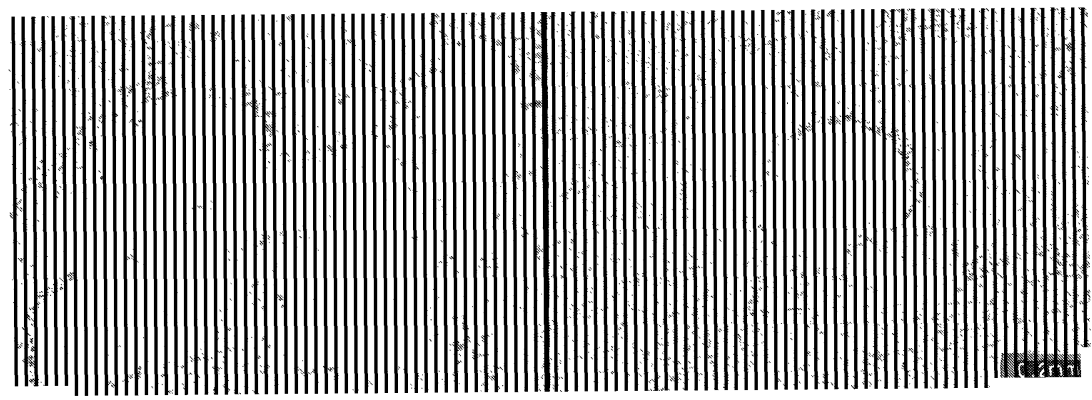


predicted for total surface area of 15 condenser tubes of high temperature portion are also shown in figures. This indicates that the probability of leakage by crevice corrosion would be very low during serviceable years, but that by pitting would be relatively high. Judging from the present data, it is unlikely to have leakage in 10 years due to pitting corroison penetration for the tube of $1.0 \mathrm{~mm}$ thickness when the growth of pitting corrosion depth is described by a logarithmic growth law. However relatively small number of pits formed causes a considerable error in prediction of the maximum value. In addition to an increase in the number of tubes to be examined each year, successive examinations of time dependence of the maximum pit depth is suggested to be done over a longer period of time.

\section{Crevice Corrosion of Pipe Joints of an Analytical Instru- ment}

A recent trend of fast chemical analysis demands the use of high pressure liquid chromatography. This has lead to the use of metallic materials for pipes and fittings instead of plastics. Since buffer solutions used for liquid chromatography show high salinity and low $\mathrm{pH}$ (Table 3), evaluation of crevice corrosion resistance is required for the joints. Pipes and fittings were sampled from high pressure liquid chromatography instruments in service for 2400 and $7200 \mathrm{hr}$. Joint connection was done by a swathed joint as shown in Fig. 9. Capillary tubes and all parts of the joint fittings were made of type 316 stainless steel. The instruments were operated at a temperature of 37 to $42{ }^{\circ} \mathrm{G}$, at a flow rate of 6.8 to $34 \mathrm{~cm} / \mathrm{s}$ and at a discharge pressure of $150 \mathrm{~kg} / \mathrm{cm}^{2}$. A severe corrosion was observed inside of a sleeve of swathed joint as shown in Photo. 3. The maximum penetration depth

Table 3. Gomposition ranges of the buffer solutions used for liquid chromatography analysis. (\%)

\begin{tabular}{|c|c|c|}
\hline & Standard analysis & In vivo analysis \\
\hline Sodium citrate & $0.774 \sim 2.667$ & $\begin{array}{c}\text { Lithium citrate } \\
0.98 \sim 4.7\end{array}$ \\
\hline Sodium chloride & $0.292 \sim 5.435$ & $\begin{array}{c}\text { Lithium chloride } \\
0.212 \sim 3.815\end{array}$ \\
\hline Citric acid & $0.61 \sim 2.0$ & $0.33 \sim 3.4$ \\
\hline Ethyl alcohol & $0 \sim 1.30$ & $0 \sim 4.0$ \\
\hline Benzyl alcohol & $0 \sim 0.5$ & - \\
\hline Thiodiglycol & $0 \sim 0.5$ & $0 \sim 0.5$ \\
\hline Brij 35 & 0.4 & 0.4 \\
\hline Capric acid & 0.01 & 0.01 \\
\hline $\mathrm{pH}$ & $3.2 \sim 4.9$ & $3.0 \sim 7.0$ \\
\hline
\end{tabular}

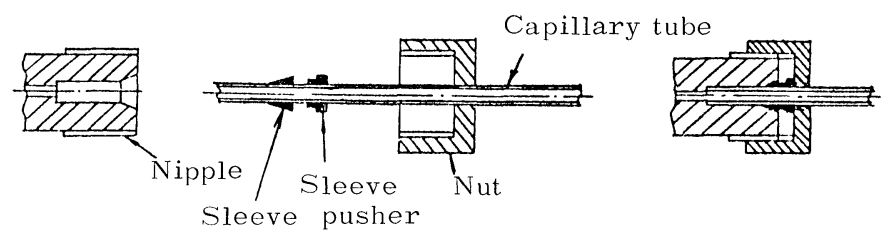

Fig. 9. A schematic description of the swathed joint used for high speed liquid chromatography. was determined for each swathed joint and plotted in an extreme value probability paper as shown in Fig. 10. It is premature to get any conclusions from these data, because of scattering and a small number of data points being available at present, but the maximum penetration depth apparently increases with service time. The evaluation of service life should be made by increasing the number of instruments to be examined, thus improving reliability of the prediction.

\section{Conclusion}

A quantitative evaluation of localized corrosion damage is attempted by means of extreme value statistical analysis. As a result, the evaluation of localized corrosion damage observed for several machine components can be made quantitatively and examination of the components with various observation time periods, having been in service, would make prediction of their service life possible.

\section{REFERENGES}

1) G. G. Eldredge: Corrosion, 13 (1957), 51.

2) D. E. Hawn: Mater. Perform., 16 (1977), No. 3, 29.

3) P. M. Aziz: Corrosion, 12 (1956), 495.

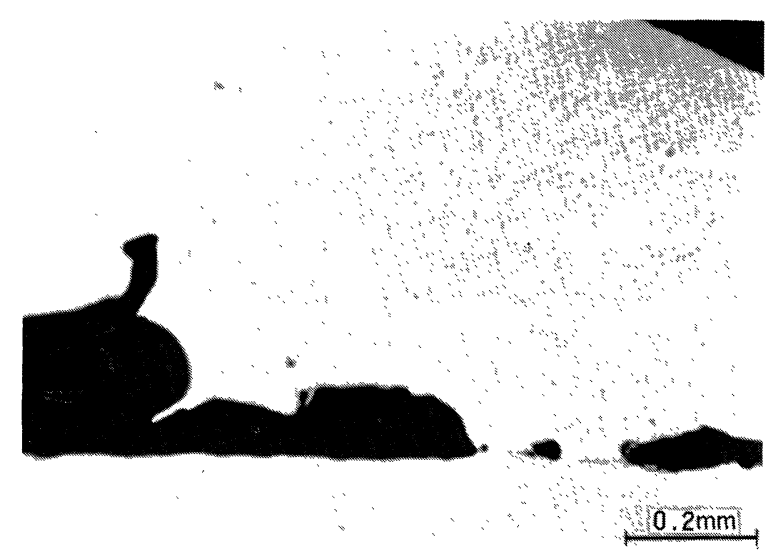

Photo. 3. Cross sectional view of crevice corrosion occurred between a sleeve and a pipe used in a swathed joint (7 $200 \mathrm{hr}$ in full service).

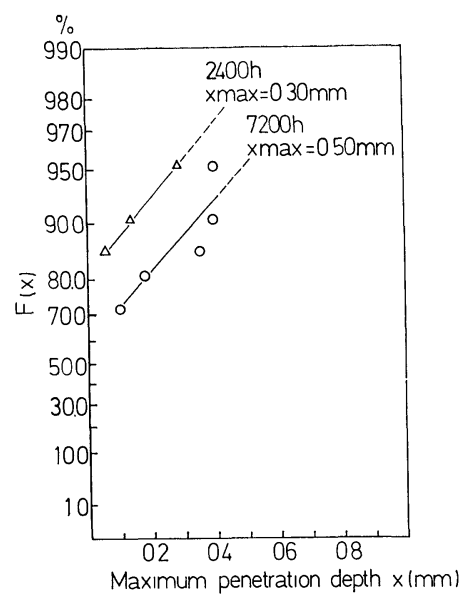

Fig. 10. Extreme value probability plots of the maximum crevice corrosion depth observed for the sleeves used in the swathed joints $\left(X_{\max }\right.$ was predicted at $T=20$ ). 
4) D. Wong and F. H. Cooks: Corroison, 36 (1980), 447.

5) D. Wong and F. H. Cooks: Corrosion, 36 (1980), 587.

6) Y. Ishikawa, T. Ozaki, N. Hosaka and O. Nishida: Environmental Degradation of Engineering Materials in Aggressive Environments, ed. by M. R. Louthan, Jr. et al., Virginia Tech. Press, Blacksburg, VA., (1981), 577.
7) Y. Ishikawa: Corrosion Engineering (Boshoku Gijutsu), 28 (1979), 278.

8) E. V. Gumbel: Statistics of Extremes, Columbia University Press, New York, (1958).

9) T. Ozaki and Y. Ishikawa: Submitted to Corrosion Engineering (Boshoku Gijutsu). 